\title{
Otomatik Portakal Filmi ve Kitabının Antisosyal Kişilik Bozukluğu Açısından İncelenmesi
}

\author{
Rufeyde SÖNMEZSOY* \\ Yüzüncü Yll Üniversitesi
}

\begin{abstract}
Özet
Anthony Burgess'ın 1962 yılında romanını yazdığı, Stanley Kubrick'in ise 1971 yılında yapımcilığını ve yönetmenliğini yaptı̆̆ı Otomatik Portakal adlı filmde, Alex'in yaşamı konu edilmektedir. Bu çalışmada da davranışçı kuram çerçevesinde antisosyal kişilik bozukluğuna sahip olan Alex'in hayatı ele alınmıştır. Alex'in hayatı üç bölümden oluşmaktadır. Alex'in hayatının ilk bölümünde, onun, antisosyal kişilik bozukluğuna sahip, empati yeteneğinden yoksun ve șiddet eğilimli bir kiși olduğu anlatılmaktadır. Bu bölümde özellikle insanlara güvenmeme konusu üzerinde durulmaktadır. Alex’in hayatının ikinci bölümünde, Alex, kaldığ cezaevinde "Suçluları Yeniden Topluma Kazandırma" projesi sebebiyle "Ludavico" adlı bir laboratuvar çalışmas ına tabi tutulmuş ve kişiliği klasik koşullanma yöntemi ile düzeltilmek istenmiş̧tir. Alex’e bunun karşsllğgnda özgürlük vaat edilmiştir. Alex'in hayatının üçüncü bölümünde, Alex'in özgürlüğüne kavuşması sonucunda yaşadıkları tedavi edilmesi ve tekrar bir çete kurarak eski günlerine dönmesi anlatılmaktadır. Hikayenin sonunda ise Alex, artık çete olaylarında zevk almadığını, evlenmek istediğini anlaması üzerine büyüdüğünü fark etmektedir. Sonuç olarak bu çalışmada, psikolojik anlamda antisosyal kişilik bozukluğu ele alınırken, bunu bireyin özgür iradesi olmadan, makine gibi otomatik bir şekilde iyi olan davranış1 seçmeye zorlanması eleştirilmektedir.
\end{abstract}

Anahtar kelimeler: otomatik portakal, antisosyal kişilik bozukluğu, klasik koşullanma, davranışçı kuram

* İletișim: rsonmezsoy @gmail.com

Gönderim Tarihi: 03.08.2016

Kabul Tarihi: 14.10 .2016 


\section{Otomatik Portakal Film ve Kitap Analizinin Antisosyal Kişilik Bozukluğu Açısından İncelenmesi}

\section{Filmin Künyesi Yönetmen:}

Stanley Kubrick

Yapımcı: Stanley Kubrick

Yapım Yılı: 1971

Senaryo: Anthony Burgess' in romanından Stanley Kubrick tarafindan senaryolaştırılmıştır.

Oyuncular: Malcolm McDowell, Patrick Magee, Carl Duering, Madge Ryan

Kurgu: Bill Butler

Yapım Yılı: 1971

Tür: Bilimkurgu, Dram ve Polisiye

Süre: $136 \mathrm{dk}$.

\section{Kitabın Künyesi}

Yazarl: Anthony Burgess

Orijinal İsmi: A Clockwork Orange

Basım Yılı: 1962

Çevirmen: Dost Körpe

Ülke: İngiltere

Özgün Dili: İngilizce

Türü: Roman

Sayfa Sayısı: 168

Yayınevi: İş Bankası Kültür Yayınları

\section{Otomatik Portakal'da Yaşananlar}

On beş yaşında bir çocuk olan Alex ve çetesinin diğer 3 üyesi olan Pete, Georgie ve Dim, içlerindeki şiddet eğilimi ile hırsılılk yapmakta, dükkânları soymakta, malları gasp etmekte, çaresiz insanlara vurup yaralamakta, kadınlara tecavüz etmektedirler.

Bir gece de kütüphaneden çıkarak evine gitmekte olan bir ihtiyara, evsiz, sarhoş ve yaşı bir adama, bir başka çete olan Billyboy ve arkadaşlarma şiddet uygularlar ve şehirdeki bir dükkâna girerek, dükkân sahibi ve eşine şiddet uyguladıktan sonra dükkânı soyarlar. Aynı gece bir araba çalarak, şehrin dışında oturan “Otomatik Portakal" adh bir roman yazmakta olan yazar Frank Alexander' in evine girip evi dağttrlar. Ortalğı kırıp dökerler, yazar Frank Alexander'ı dövdükleri ve etkisiz hale getirdik leri gibi, bu 4 kişilik çete yazarın karısına da tecavüz ederler.

Alex, çetenin diğer üyeleri ile çetenin liderinin kim olduğu hakkında bir tartısma yaşar ve kendi çetesinin üyelerinden Georgie ve Dim ile kavga eder. Alex bu kavgadan sonra arkadaşları ile konuşur ve aralarındaki sorunu hallettiklerini düşündükten sonra evine döner. Ve gecenin bir yarısında dinlemekten zevk aldığı Beethoven' in 9. senfonisini plağa yerleştirdikten sonra evde uyuyan anne ve babasının ya da apartmanda kalan diğer insanların rahatsı olabilecekleri ihtimalini umursamadan müziğin sesini sonuna kadar açarak dinlemeye başlar. Ertesi gün yorgun olduğunu hissetmesi ve uyumak istemesi nedeniyle okula gitmek istemez ve daha önce sslahevine girmesi nedeniyle kendisi ile ilgilenen Eğitici Danışmanı P.R. Deltoid onu ziyarete gelir. P.R. Deltoid bir gece önceki olaylardan ve bu olaylarda Alex'in isminin 
geçtiğinden bahseder ve onu iyi bir çocuk olması noktasında uyararak bir daha başının belaya girmesi durumunda hapishaneye gönderileceğini söyler. Alex, daha sonra dinlemekten zevk aldığı plakların satıldı̆̆ müzik markete gider ve orda iki genç kızla tanışarak onları evine davet eder ve bütün gün defalarca bu iki genç kı ile birlikte olur.

Akşamüstü çetenin diğer üyeleri Alex'in ailesi ile birlikte kaldıkları apartmanın önünde Alex’i beklerler. Onların kendisini beklediklerini gören Alex şaşırır. Arkadaşları ile evinde pahah antikaların bulunduğu ve kedileriyle birlikte yaşayan kadını evine girerek hırsılık yapma planları kurarlar. Alex, çetenin diğer üyeleri ile birlikte yaşh kadının evine gider fakat yaşh kadın onlara kapıyı açmaz ve şüphelenerek polisi arar. Alex, arkadaşlarına grubun lideri olduğunu ispatlamak amacıyla yaşlı kadının kediler ile dolu evine tek başına girmeye karar verir. Alex evden içeri girer, onu gören yaşlı kadın ile kavga etmeye başlar ve kendisine direnen yaşl kadını öldürür. Bu sırada polisin siren sesi gelir, kaçmak için dı̧arı çıkan Alex, çetenin diğer üyelerinin şiddetine maruz kalır, Çetenin diğer üyeleri kaçar fakat Alex, polis tarafindan yakalanır, hapishaneye gönderilir ve 14 yil ceza alır.

Alex, kaldığı cezaevinde "Suçluları Yeniden Topluma Kazandırma" projesi sebebiyle "Ludavico" adlı bir laboratuvar çahş̧̧asına tabi tutulmuş ve kişiliği düzeltilmek istenir. Alex, bu çalısmanın kobayı seçilir. Alex, yaklaşık olarak 2 hafta bu deneyin kobayı olacak ve sonra serbest bırakılacaktır. Bu çalısmanın seanslarında Alex'e, şiddet dolu filmler izlettirilir, fiziki işkencelere maruz bırakılır, acılar çektirilir. En sonunda Alex aklından kötülük geçtiği anda kusacak ve acılar çekecek hale getirilir. Bu yöntemle tedavi edilen Alex artık kötülüğü düşünmeyecek hale gelir.

Beethoven dinlemeyi çok seven Alex, şiddet içerikli izletilen filmlerde fon müziği olarak Beethoven' in 9. senfonisinin tesadüfen verilmesi üzerine artı çok sevdiği bu müziği dinlerken de kusacak ve acilar çekecek bir hale gelir.

Böylece kişiliği değişen Alex, bir kuklaya dönüşür. Artı en çok sevdiği Beethoven'1 ve müziği de dinleyemez hale gelir. Fakat tedavi sonrasında kayitlara iyileşmiş olduğu yazilır ve cezaevinden salıverilir.

Alex, evine döndüğünde, odasmmn tamamen değiştiğini, odasında kendisine ait hiçbir eşyanın kalmadığını görür. Alex, ailesinin kendi odasmı Joe isimli bir gence kiraladığını öğrenir. Ayrıca Alex kendisine ait olan bütün eşyalara devlet tarafindan el konulduğunu öğrenir. Bunun üzerine Alex evi terk eder ve gidecek bir yeri olmadığından Alex evsiz kalır.

Alex, yaşadığı acılara katlanamayaca ğını düşünür ve intihar etmeye karar verir. Nasıl intihar edeceğini bilmeyen Alex, halk kütüphanesine giderek bunu bir kitaptan öğrenmesi gerektiğine kara verir. Halk kütüphanesine giden Alex, daha önce çetesi ile birlikte darp ettiği bir ihtiyar adamla kütüphanede karşlaşır ve ihtiyar adam Alex’i tanır. Halk kütüphanesinde bulunan yaşlıların Alex’i darp etmesi üzerine, Alex'in 'aynası' diye tabir ettiği polisler gelir. Alex, gelen polislerden birinin eski çetesinin üyelerinden olan Dim olduğunu görür, diğer polis ise daha önce bir tartı̧mada darp ettiği Billyboy isimli bir gençtir. Dim ve Billyboy, Alex'i tanirlar ve onu sssı bir yere götürerek darp eder ve orda birakırlar.

Alex, yaralı bir şekilde bir eve sığınır ve bu evin daha önce evine girerek darp ettikleri ve karısma tecavïz ettikleri 'Otomatik Portakal' yazarmın evi olduğunu görür. Alex, sosyalist yazar Frank Alexander'1 tanır fakat olayın yaşandı̆̆ gece kendisi ve çetesi maske kullandikları için sosyalist yazar Alex’i tanımaz. Frank Alexander, Alex'in devlet tarafindan "Ludavico" deneyine maruz birakılan, daha sonra serbest brrakılarak gazetelere resmi basılan tutuklu olduğunu anlar. Yazar Alexander bir yandan Alex’ten intikamını almak ister, diğer yandan ise arkadaşları ile birlikte hükümete karşı Alex’i kullanmak ister. Bu nedenle Alex’e yardım etmek istediğini söyler. Yazar Frank Alexander ve arkadaşları Alex’i bir eve kapatır, yan tarafta bulunan evden ise Alex'in çok sevdiği Beethoven'in 9. senfonisinin sesini sonuna kadar açarlar. Alex, 'hastalık' diye tabir ettiği kusma ve acı çekme belirtilerini yaşamaya başlar ve daha fazla dayanamayarak intihar eder fakat ölmez. Bu olayın basına yansıması üzerine, onu makineye dönüştüren hükümet tekrar eski haline geri getirir. 
Kitaba göre; Alex, 18 yaşına geldiğinde, yaptı̆̆ ş̧eylerin artık kendisini mutlu etmediğini fark etmeye başlar. Çetenin son üyesinin evlenmiş olduğunu görür ve kendisinin de artk daha sakin bir hayat sürmesi gerektiğine karar verir (Burgess, 2015).

\section{Antisosyal (Toplumdışı) Kişilik Bozukluğunun Alex Karakteri Açısından Ele Alınması}

\section{Antisosyal (Toplumdışı) Kişilik Bozukluğu}

Amerikan Psikiyatri Birliği (2014), antisosyal kişilik bozukluğuna sahip olan bireyleri tutuklanmasına yol açan yineleyici eylemlerde bulunma, sık sk yalan söyleme, kendi çıkarları için başkalarını kullanma, geleceği planlamadan dürtüsel olarak hareket etme, skk skk kavga ve dövüşlere katılarak kendisinin ya da bir başkasının güvenliğini umursamama, bir işin ve parasal yükümlülüklerin sorumluluğunu taşıyamama ve başkasına verdiği zarardan ötürü vicdan azabı duymama gibi davranış örüntülerini gösteren bireyler olarak tanımlamıştır. Amerikan Psikiyatri Birliği (2014), bu tanı kriterlerinin en az üç tanesine sahip olma durumunda 15 yaşın altında olan bireylere davranım bozukluğu tanısını koyarken 18 yaş üstünde olan bireylere antisosyal kişilik bozukluğu tanısını koymaktadır.

Antisosyal kişilik bozukluğuna sahip bireylerin 'yakalanmadan atlatabiliyorum, dolayısıyla olası kötü sonuçları için üzülmeye değmez, yakalanmadığın sürece yalan söyleyebilir ve insanları kandırabilirim, işlerin yapılabilmesi için en iyi yol zorlamak ya da kurnazlık yapmaktır, verilen sözlerin tutulması ya da borçların ödenmesi önemli değildir, başka insanların çok büyük zayıflıkları var ve kandırılmayı hak ediyorlar' gibi yerleşik düşüncelere sahip olduğu görülmektedir (Köroğlu ve Bayraktar, 2014).

Yapılan araştırmalarda elde edilen bir diğer önemli bulgu, çocukluk çağında aile içi şiddet, vücutta ağır yaralanma, şiddetli dayak, kötü muamele, anne-babadan ayrılma, fiziksel taciz, cinsel taciz ya da ihmal gibi travmalara maruz kalan çocuklarda ilerleyen dönemlerde antisosyal kişilik bozukluğunun geliştiği görülmektedir. (Algül ve diğerleri, 2009).

$\mathrm{Bu}$ kişiler sik skk karakola düşer fakat olumsuz deneyimlerinden ders almazlar. Çoğunda bu davranış bozuklukları yaklaşı 40-50 yaşından sonra görece azalır; kişinin çok sorunlu yaşamı bir miktar yatışır, fakat bencillik ve sorumsuzluk sürer. Toplum içinde ve aile yaşamında çeşitli sorumsuz davranış örnekleri gösterirler. Sürekli ve tutarlı bir ilişki kuramazlar, kursalar bile kısa süreli ve aldatıcı olur. Dürtülerini engelleyemez, denetimsiz, atak ve saldırgan davranışlar gösterirler. Üstbenlik gelişmemiştir, dürtüsel doyum, haz ilkesi her şeyin üstündedir, genellikle suçluluk duymazlar, pişmanlıkları olsa bile yüzeysel ve geçicidir. Dıştan gelen engel ve yargılara aldırmazlar, kendilerini haklı çıkarmak için akla uygunlaştırma (rasyonalizasyon) ve acting out (kişinin, çatışma veya stresle duygu veya düşünce yoluyla değil de eylem yoluyla başa çıkma yöntemi) savunma düzeneğini fazla kullanırlar (Doksat, 2008; Öztürk ve Uluşahin, 2008).

Yapılan çalşsmalarda; antisosyal kişilik bozukluğuna sahip olan bireylerin eğitim sürelerinin kısa ve işsizlik oranlarının ise yüksek olduğu bulunmuştur (Türkçapar, Güriz, Özel, Işık ve Dönbak, 2004).

\section{Alex’in Yaşamında Antisosyal (Toplumdışı) Kişilik Bozukluğu}

Otomatik portakalın filmini izlerken veya kitabını okurken, sı sk yalan söyleyen, takma isimler kullanan, kendi kişisel çıkarı ve zevki için başkalarının haklarını gasp eden, hırsılık yapan, kendisinin veya başkalarının güvenliğini umursamayan, tutuklanmasına yol açacak davranışları sık sk tekrarlayan, sürekli kavga ve dövüşlere katılan, saldırganca davranışlar sergileyen, geleceği hiçbir şekilde planlama yan ve dürtüsel davranan Alex'in hikâyesi gözler önüne serilmektedir. 
Filmin ilk dakikalarından ve kitabın ilk sayfalarından itibaren Alex'in antisosyal kişilik bozukluğunun özelliklerine sahip olduğu görülmektedir. Ayrıca Alex'in hem filmin hem de kitabın anlatıcısı olduğu anlaşılmaktadır. Alex'in çetenin diğer 3 üyesine göre yaşının küçük olmasına rağmen, onlara liderlik yaptığı, onları yönettiği ve kendi istedikleri doğrultusunda kullandığı görülmektedir.

Kitapta 15 yaşında olduğu belirtilen Alex'e DSM-V kriterlerine göre antisosyal kişilik bozukluğu tanısı konulamamakta, davranım bozukluğu tanısı konulmaktadır. Fakat filmde Alex'in 18 yaşından büyük olduğu gözlemlenmekte bu nedenle antisosyal kişilik bozukluğu tanısı konulabilmektedir.

15 yaşında olan Alex'in yaşamına bakıldığında; kütüphaneden çıkan ve evine doğru giden yaşh adama ve sokakta içkili bir şekilde duran kimsesiz bir yaşlıya karşı Alex ve çetesinin yaptıkları saldırganca davranışlar, "Otomatik Portakal" kitabının yazarının evine izinsizce girerek, yazarı darp etmeleri, ve yazarın gözünün önünde eşine çetenin 4 üyesinin birden tecavüz etmeleri, kedileri ile birlikte yaşayan kadının evine izinsiz girerek kadını öldürmeleri, diğer bir sokak çetesi olan Billyboy isimli çocuk ve arkadaşları ile ortada hiçbir neden yok iken kavga etmeleri davranım bozukluğuna özgü davranışları sergilediklerini açık bir şekilde göstermektedir. Bu yaşananlara bakıldığında Alex ve çetesinin kendi istekleri doğrultusunda geleceği tasarlamadan, dürtüsel davrandıklarını, empati yeteneğinden yoksun olduklarını, kendilerinin veya bir başkasının güvenliğini umursamadıkları görülmektedir.

Alex ve çetesinin yazarm eşine tecavüz etmeleri ve Alex’in evine aldığı iki genç kızla bütün gün defalarca birlikte olması antisosyal kişilik bozukluğunun özelliklerinden olan dürtüsel davranmanın, insanlardan kişisel çıkar sağlamak ve zevk almak için cinsel ilişkide bulunmanın göstergesidir.

Alex ve çetesinin yaptikları toplum dişı saldırganca davranışları öncesinde herhangi bir şekilde planlamadan, bir öngörüde bulunmadan, anlık olarak karar verdikleri görülmektedir. Bu davranışlara bakıldığında Alex ve çetesinin dürtüsellik ile hareket ettikleri ya da geleceği planlayamadıkları görülmektedir.

Filme oranla kitapta Alex'in daha fazla dilbaz olduğu, kavramlara farkh takma isimler taktığ, daha konuşkan olduğu ve insanları bu şekilde etkilemeyi başardığ görülmektedir. Kitabı okurken, Alex'in örneğin polislere 'aynasızlar', yaşh insanlara karşı 'moruk', kavga etmekten bahsederken 'marizlemek', tecavüze 'gir-çık oyunu' gibi kelimeleri kullanması onun bu dilbazlığının bir göstergesidir. Ve yine kitapta, Alex'in yanında kendisi için ağlayan annesinin ağlama şekli ile 'ühüü ühüü' diye dalga geçmesi, kendisi için hiçbir şey ifade etmemesi, acı çeken kişilere karşı duyarsı, vurdumduymaz olduğu ve empati yeteneğinden yoksun olduğu görülmek ted ir.

Alex'in insanlar ile konuşurken gayet rahat bir şekilde ve sürekli küfürlü konuştuğu, tecavüz etmek gibi ciddi bir olayı hafife alarak bunu 'gir-çık oyunu' olarak isimlendirdiği ve kurduğu hayaller ile gördüğü rüyaların sürekli şiddet içerikli olduğu görülmektedir. Alex'in bunları anlatırken çok rahat olduğu bu durumdan zevk aldığı, aslında anormal olan bütün bu durumları mantığa bürüyerek insanların bunları hak ettiğini düşünerek normalleştirdiği görülmektedir.

Kitabı okurken, Alex ve çetesinin hırsızlık yaparak ele geçirdikleri paraları çarçur ettikleri, gittikleri barlardaki fakir insanlara içki ikram ederek yaptıkları hırsızlığı mantığa bürüdükleri, yaptıkları hırsızlık ile ilgili hiçbir şekilde vicdani bir rahatsızlık duymadıkları anlaşılmaktadır. Alex'in tutuklanması sürecinde, polislere yaşlı kadını öldürmek istemediğine, bunu kendisi yapmadığına, arkadaşları tarafindan tuzağa düşürüldügüune, kendisinin aslında kötü bir insan olmadığına dair polisleri ikna etmeye çalıştığ1 görülmektedir. Tüm bu yaptıklarına rağmen Alex’in polislerin kendisine iyi davranmasını beklediği görülmektedir.

Alex'in Eğitici Danışmanı P.R. Deltoid ile yaptığı konuşmada, Alex'in daha önce sslahevine girdiği ve P.R. Deltoid'in kendisine Eğitici Danışmanı olarak verildiği, suça karışmaması ve hapishaneye girmemesi için Deltoid'in, Alex'i sürekli takip ve kontrol ettiği görülmektedir. Alex ve çetesinin Billyboy ve arkadaşları ile kavga ettiğini öğrenen Deltoid'in Alex'i uyardığını, Alex'in ise kendine güvenli ve bilgiçlik taslayan 
bir tavır ile yaşanan olay ile bir alakasının olmadığını, son zamanlarda hiçbir olaya karışmadığını söylediği ve kendisine güvenmesini istediği görülmektedir. Bu durum antisosyal kişilik bozukluğuna sahip olan bireylerin ceza durumundan kaçınmaları ve yaptıklarına kılıf bulmaları ile ilgili özelliklerini gözler önüne sermektedir. Antisosyal kişilik bozukluğu örüntüsüne sahip olan Alex için de yaptığı kötü şeyler ortaya çıkmadığı, kanit olmadığı ve ispatlanmadığ 1 sürece hiçbir sorun olmadığ1 görülmektedir.

Alex'in davranışlarını "normal" olarak algılaması, yaptıklarından hiçbir şekilde pişmanlık duymaması ve yaptıklarını ya da yapacaklarını mantığa bürüyerek etkileyici ve şïrsel bir şekilde konuşması kitapta ki şu sözlerden anlaşılmaktadır; "...P.R. Deltoid denen lavukla kankalarının kaygilarına sırıttım. Tamam, kabahat işlediğim oluyordu, soygun ve darp ve usturayla adam kesmek ve tecavüz filan gibi... Enselenirsem, eh, ne yapalım yani, hem ülkedeki herkes benim gibi değildi ki ey küçük kardeşlerim. Enselenirsem bir mekanda üç ay yatardm, bir başka mekanda da altı ay ve sonra, P.R. Deltoid'in beni gayet müşfikçe uyardı̆̆ı gibi, büyüklerimin sınırsız sevecenliğine karşın o koca dünya dışı hayvanat bahçesine tıkılırdım, ama diyorum ki: 'Tamam, ama acıyın bana efendiler, çünkü kapalı kalmaya dayanamam. Bıçaklanmama veya kanım otobanda yamulmuş metallere ve parçalanmış camlara son bir nakarat halinde fişkırana kadar, önümde kar ve zambak beyazı kollarını açan gelecekte bütün çabam tekrar enselenmemem olacaktır..." (Burgess, 2015, s.35). Alex'in bu sözlerinden tutuklanmasına yol açacak olan yineleyici eylemlere devam edeceği ve tek sorunun yakalanmak ya da yakalanmamak olduğu anlaşılmaktadır.

Hem filmi izlerken hem de kitabı okurken dikkat çeken bir diğer nokta ise Alex’in anne ve babası ile olan ilişkisi de dâhil olmak üzere ilişkilerinin hep yüzeysel olduğu, kurduğu ilişkileri ise daha çok çıkar amaçh kullandığ1 görülmektedir. Yine Alex’in ailesi de dâhil olmak üzere hiç kimseye güvenmediği ve ailesinin kendisinden çekindiği görülmektedir.

Aynı zamanda kitabı okurken, Alex ve çetesinin antisosyal kişilik bozukluğu örüntüsüne eşlik eden madde kullanım bozukluğuna sahip oldukları, 'Korova Barı'ında' içtikleri sütün içine kullandıkları maddeyi katarak içtikleri ve bu maddeye "katkılı sütteki bıçaklar" diye isimlendirdikleri görülmektedir.

Alex'in şişik benlik algısını, çetesinin içinde yaşça en küçük olmasına rağmen lider olma isteğini ve kendini üstün görmesini kitapta geçen “.... moruk pilice ve gerekirse pisiciklerine tek başıma ölçüsüz şiddet uygulayacaktım, sonra da cidden işe yarar görünen şeyleri avuç avuç alıp ön kapıdan vals yaparak çıkacak ve bekleyen kankalarımın üstüne altın ve gümüş yağdıracaktım. Liderlik neymiş öğrenmeliydiler" (Burgess, 2015, s.53) sözleriyle anlaşılmaktadır. Ayrıca Alex'in kitabın anlatıcısı olarak, kitabı okuyan kişilere sürekli 'ey küçük kardeşlerim' diye hitap etmesi de bu durumu ortaya koymaktadır.

Alex'in empati yeteneğinden yoksun ve duygusuz olduğunu, başkasının acısını yok saydığını ve yaptığı işkenceden zevk aldığını kitabın ve filmin bir çok yerinde görmekle birlikte bu durum kitapta “... sonra vals yaparak sağ ve sol yanaklarını yarmak, böylece kış yıldızlarının ışığında o pis, yağh dobişko burnunun iki yanından aynı anda, sanki iki perde iner gibi kan boşalmasını seyretmek cidden çok tatmin edici oldu kardeşlerim" (Burgess, 2015, s.15) sözleriyle ifade edilmektedir.

Girdiği cezaevinde on dört yll ceza almış olmasına rağmen, cezaevinden çıtı̆̆ında tekrar bir çete kurup önce kendisine tuzak kuran diğer çete üyelerine şiddet uygulayaca ğ 1 ve sonrasında ise eski saldırganca davranışlarını devam ettireceğine dair hayaller kurmaya devam etmesi ise Alex'in tekrardan tutuklanmasına yol açan yineleyici davranışlarda bulunacağını, yaptıklarına kılıf bulacağını ve hiçbir şekilde vicdan azabı çekmeyeceğini ortaya koymaktadır.

Filmde de görüldüğü gibi antisosyal kişilik bozukluğuna sahip olan bireylerde yetersiz bir vicdani gelişim olmakla birlikte entelektüel gelişimleri iyi bir düzeydedir. Nitekim Alex'in giyimine özen göstermesi ve modaya uygun giyinmesi aynı zamanda dinlediği müzik tarzı onun entelektüel gelişimini göstermektedir. Alex, şiddet uygularken ve tecavüz ederken de estetik bir yol seçmekte ve sevdiği şeyleri yaparken sanatsal yönünü göstermektedir. Bu durum etik değerlerden yoksun olan Alex’in estetik anlayışının gelişmiş olduğunu gözler önüne sermektedir. 
Alex'in "Ludavico" isimli deneyde kobay olması ve davranı̧larında bir düzenleme yapılmasına rağmen aslında içindeki şiddet uygulama, dürtüsel hareket etme ve geleceği planlama durumlarının yok olmadığı ve bir empati yeteneği geliştirmediği görülmektedir. Bu deney sonucunda Alex, aynı hislere sahip olduğunda 'hastalik' diye tabir ettiği bir takım bedensel sorunlar hissetmekte, kusmak istemekte ve acı çekmektedir.

Kitapta, insanların iyiliği seçerek ve bu şekilde davranarak bir hayat sürmeyi tercih edebildik leri gibi, aynı şekilde kötülüğü de tercih edebildikleri ve bu şekilde hayat sürdürdükleri anlatılmaktadır. Yazar buna karşın bu seçimlerin özgür irade ile mi yoksa insanın elinde olmayan, dürtüsel bir şekilde yapıldığını mi sorgulamaktadır.

\section{Antisosyal (Toplumdışı) Kişilik Bozukluğunda Sağaltım}

Antisosyal kişilik bozukluğuna sahip olan kişilerin sağaltım için başvurmaları nadirdir. Bu bozukluğu olan kişiler daha çok suç işledikten sonra bir hekime bu kişi hakkında değerlendirme yapması amacıyla yönlendirilir, nadir olarak da sağaltım için gönderilirler. Gerçekten kişiliğindeki temel bozukluğun bilincine varı, değişmek amacıyla başvuranlar nadirdir (Öztürk ve Uluşahin, 2008).

Yakımmaları kendilerine değil, çevreye yönelik olduğundan sağaltıma başvurmak için nedenleri yoktur. Ancak, başı sıklkkla derde giren, başarısız ve mutsuz olan ya da madde kullanım bozukluğu, cinsel sorunlar, nörotik belirtiler, aile geçimsizliği gibi sorunları olan kişiler hekime başvurabilir (Öztürk ve Uluşahin, 2008). Suç işleyerek cezaevlerine girenler, cezaevlerinde uygulanan rehabilitasyon programlarına katılabilirler (Butcher, Mineka ve Hooley, 2013). Alex, kendisiyle ilgili herhangi bir sorun olmadığını, yaptığı davranışları insanların hak ettiğini, güçlü olduğu sürece ezilmeyeceğini, tam tersine bir başkasına zarar verme hakkına sahip olduğunu düşünmektedir. Alex, bütün sorunun çevresinden kaynakladığını düşünmekte ve hiçbir şekilde tedavi olmak için hekime başvurmamaktadır.

İşlediği suçun sonuncunda yakalanan Alex'in, cezaevinde davranışçı terapi ile rehabilite edilmeye çalışıldığı görülmektedir. Hükümetin 'Ludavico' isimli deney çalışması ile Alex, davranışçılık kuramında belirtilen klasik koşullanma yöntemi ile koşullandırılmaktadır. Bu deney çalışmasında Alex’e şiddet görüntüleri izletilmeden önce Alex'in 'hastalk' diye tabir ettiği mide bulantıs1, iğrenme gibi belirtilere sebep olan bir ilaç verilmektedir. Bu ilacın etkileri ortaya çıtığı sırada Alex’e şiddet görüntüleri izletilmekte ve ilk etapta zevk alarak izlediği filmleri Alex, bir süre sonra izleyememekte ve hastallk belirtileri ortaya çıkmaktadır. Cezaevinde, davranış̧ı kuramın klasik koşullanma yöntemi ile rehabilite edilerek serbest birakılan Alex, geçmişteki hayatında olduğu gibi insanlara şiddet uygulama, tecavüz etme ve zarar verme gibi davranışları uygulamak istediğinde, hastalk belirtileri ortaya çıkmakta ve Alex mecburen iyi olan davranışı seçmektedir. Alex, kendisine uygulanan bu tedavinin sonucunda, aslinda insan olmaktan çıkıp, hükümet tarafindan toplumun istediği davranışları uygulana bir 'otomatik portakala' dönüşmüştür.

İnsanların otomatik bir makineye dönüştürülmesine karşı olan bir grup insanın hükümete başkaldırması ve bunun için Alex’i kullanmaları sonucunda hükümet Alex’i eski haline dönüştürmüştür. Bu dönüşüm de, Alex'in şiddet davranışlarına karşı geliştirdiği koşullanma söndürülmüş ve Alex eski şiddet dolu hayatına geri dönmüştür.

Alex'in hayatında da görüldüğü üzere, antisosyal (toplumdısı) kişilik bozukluğunda daha fazla ve daha iyi bir sağaltım için dahi etkin tedavi güç bir görevdir. Birçok klinik araştırmacı bu bozuklukların tedavisinin günümüzde olanaksı olmasa bile çok güç olduğu sonucuna ulaşmıştır (Butcher ve diğerleri, 2013).

$\mathrm{Bu}$ nedenle de bu alanda çalşsan kimi uzmanlar günümüzde antisosyal kişilik bozukluğu-na sahip olan kişilerin tedavisinden çok yönetiminin düşünülmesi gerektiği sonucuna ulaşmışlardır (Butcher ve diğerleri, 2013). 
Antisosyal kişilik bozukluğunun suça yönelik etkinlik leri 40 yaşından sonra tedavi olmazsa azalma göstermektedir. Bunun olası nedeni biyolojik dürtülerin zayıflaması, kendine zarar veren davranışları daha iyi kavraması ve sosyal koşullanmanın biriken etkileridir. Bu azalma ise sadece antisosyal davranışı boyutudur; benmerkezci, duyarsı ve istismarcı duygulanımsal ve kişiler arası boyut varlığını sürdürmektedir (Butcher ve diğerleri, 2013). Yaş ile ilgili olan bu durum 'otomatik portakal' filminde gösterilmezken, kitabında belirtilmektedir. Alex, 'Ludavico' deneyinden sonra tekrar eski haline döndürülmüş ve şiddet dolu hayatına devam etmiştir. Fakat eski kurmuş olduğu çetenin üyelerinden biriyle bir kafede karşılaşması ve arkadaşının evlenerek düzenli bir hayat sürüyor olması Alex’i etkilemiştir. Bu etkilenmenin sonucunda Alex, kendisine zarar veren davranışları düşünerek öyle bir hayat sürmek istemediğini fark etmiştir.

$\mathrm{Bu}$ vakalar kendi sıkıntıları kadar, birlikte yaşadıkları kişiler için de ciddi bir sıkıntı ve stres kaynağı olabilmektedirler. Üstelik hasta olarak görülmediklerinden, etraflarında, bilerek ya da insanları üzmek ya da kırmak amacıyla böyle davrandıkları sanılır. Aileler genellikle bu kişilere böyle davranmaktan vazgeçmeleri için baskı yaparlar, akıl ve öğüt verirler ve tedavi için pek özendirmezler. Bazı aileler ise, durumu bir hastalk olarak görmeyi tercih eder ve durumu kabullenip düzelmesi konusunda çaba göstermezler. Alex'in ailesinde de bu durum görülmektedir. Alex'in anne ve babasının, kendisi için tedirgin oldukları fakat onun hayatına hiçbir şekilde müdahale etmedikleri görülmektedir. Öyle ki annesi Alex'in odasın dahi girememektedir. Yine Alex'in Eğitici Danışmanı P.R. Deltoid'in kendisine vermiş olduğu akıl ve ögütleri Alex’in dinlemediği ve önemsemediği görülmektedir. Bu nedenle antisosyal (toplumdı̧ı) kişilik bozukluklarının tedavisinde hasta yakınlarının sabırl, anlayışlı ve destekleyici yaklaşımları yanında düzenli ve uzun süreli terapilerle sonuç alınabileceğini bilmelerinde ve sık hekim değiştirmeme lerinde yarar vardır (Şahin, 2009).

\section{Sonuç}

Antisosyal (toplumdış1) kişilik bozukluğuna sahip olan bireyler, kendilerinin ve başkalarının güvenliklerini hiçbir şekilde umursamadan şiddet davranışlarını gösterebilmektedirler. Alex'in hayatına bakıldığında, onunda antisosyal kişilik bozukluğunun tüm belirtilerini taşıdığı ve hapishanede yapılan bir deney sonucunda koşullandırılarak bir makinaya dönüştürüldüğü görülmektedir. Alex’in sergilediği şiddet dolu davranışlar, kendisine ve etrafindaki insanlara zarar vermekte ve Alex bu davranışlarını sürdürmek istemektedir. Öte yandan kendisine uygulanan deney sonucunda davranış̧̧ı terapi ile klasik olarak koşullandırılan Alex, iyi olan davranışı kendi isteği ile tercih etmemektedir. Yazar, 'otomatik portakal' eserinde, bir yandan antisosyal kişilik bozukluğu örüntüsünü gözler önüne sererken diğer yandan bireyin özgür iradesi olmadan, makine gibi otomatik bir şekilde iyi olan davranışı seçmeye zorlanmasını eleştirmektedir. 


\section{Kaynaklar}

Algül, A., Ateş, M.A., Gülsün, M., Doruk, A., Semiz, Ü.B., Başoğlu, C., .. Çetin, M. (2009). Antisosyal kişilik bozukluğu olgularında kendini yaralama davranışının saldırganlık, çocukluk çağı travmaları ve dissosiyasyon ile ilişk isi. Anatolian Journal of Psychiatr, 10, 278-285.

Amerikan Psikiyatri Birliği, (2014). Ruhsal bozuklukların tanısal ve sayımsal el kitabı DSM-V (5. Baskı). Çeviren: E. Köroğlu. Ankara: Hekimler Yayın Birliği.

Burgess, A. (2015). Otomatik portakal (22. Baskı). Çeviren: D. Körpe. İstanbul: Türkiye İş Bankası Kültür Yaymları.

Butcher, J.N., Mineka, S. ve Hooley, J.M. (2013). Anormal psikoloji. Çeviren: O. Gündüz. İstanbul: Kaknüs Yaymlar1.

Doksat, M.K. (2008). Kişilik bozuklukları. İstanbul Üniversitesi Tıp Fakültesi Sürekli Tıp Ĕ̈itimi Etkinlikleri, Türkiye'de Sık Karşılaşılan Psikiyatrik Hastalıklar Sempozyum Dizisi, 62, 239-254.

Köroğlu, E., Bayraktar, S. (2014). Kişilik bozuklukları (4. baskı). Ankara: Hekimler Yayın Birliği.

Öztürk, M.O. ve Uluşahin, A. (2008). Ruh să̆lı̆̆ ve bozuklukları (11. baskı). Ankara: Nobel Tip Kitapevleri.

Şahin, D. (2009). Kişilik bozuklukları. Klinik Gelişim Dergisi, 22 (4), 45-55.

Türkçapar, H., Güriz, O., Özel, A., Iş̧k, B. ve Dönbak S. (2004). Antisosyal kişilik bozukluğu olan hatalarda öfke ve depresyonun ilişkisi. Türk Psikiyatri Dergisi, 15 (2), 119-124. 


\section{Summary \\ An Investigation of Film and Book of A Clockwork Orange According to Antisocial Personality Disorder}

A Clockwork Orange, written by Anthony Burgess in 1962, produced and directed by Stanley Kubrick in 1971, plots Alex's life. In the present article, main character's personality disorder was discussed according to behaviorist theory. Alex's life consists of three parts. In the first part of his life, he is described as, with an antisocial personality disorder, having lack of empathy and being a person prone to violence. This part specifically focused on the matter of trusting people. In the second part of Alex's life, Alex was subjected to a laboratory study "Ludavico", which is a part of a project called "Reintegrating Offenders to Society" and he was treated to shape his personality with classical conditioning. In exchange for that, Alex has been promised his freedom. In the third section of Alex's life, his life after emancipation - the treatment and re-establishment of a gang to return to the old days - is discussed. At the end of the story, Alex realizes that now he did not enjoy the gang life, wanted to marry which points out that he has grown up. Consequently, the present article criticizes the psychological perspective that forces individuals who have antisocial personality disorder to choose good manners automatically like a machine without of their freewill.

Keywords: A clockwork orange, antisocial personality disorder, classical conditioning, behavioral theories. 